\title{
Scale dependency and functional response in moose habitat selection
}

\author{
Ivar Herfindal, Jean-Pierre Tremblay, Brage B. Hansen, Erling J. Solberg, Morten Heim and \\ Bernt-Erik Sæther
}

I. Herfindal (ivar.herfindal@bio.ntnu.no), Centre for Conservation Biology, Dept of Biology, Norwegian Univ. of Science and Technology, NO-7491, Trondheim, Norway, and Museum for Natural History and Archaeology, Norwegian Univ. of Science and Technology, NO-7491, Trondheim, Norway. - J.-P. Tremblay, Dépt de biologie and Centre d'études nordiques, Univ. Laval, QC, Canada, G1V 0A6. - B. B. Hansen and B.-E. Sather, Centre for Conservation Biology, Dept of Biology, Norwegian Univ. of Science and Technology, NO-7491, Trondheim, Norway. - E. J. Solberg and M. Heim, Norwegian Inst. for Nature Research, NO-7485 Trondheim, Norway.

\begin{abstract}
Habitat selection can be influenced by the distribution of the habitat types in the landscape as well as net gain in visiting patches of resources, causing individual variation in habitat selection. Moreover, the hypothesis of functional response in habitat selection predicts that the degree of selection of a resource depends on its relative availability. We used radio-telemetry data from individual moose on an island off the coast of northern Norway to evaluate whether the selection of habitat types at the landscape scale differed from the choice of habitat types within the home range, and investigated the functional response in habitat selection by relating individual habitat selection to home range characteristics. At the landscape scale, moose selected for habitat types that provided both good forage and cover, with small differences between sex and age groups. At the home range scale, all individuals selected habitat types that were associated with cover and low human impact. Habitat selection was not modified by local moose density, but was related to home range size at both spatial scales. Larger home ranges contained larger proportions of non-preferred habitat types compared to smaller home ranges. At the home range scale, the selection for a habitat type decreased with its relative availability, indicating a functional response in habitat selection. This suggests that habitat selection is modified by home range size, which influences the availability of habitat types and shapes individual habitat selection patterns. Our results support previous suggestions that analyses of habitat or resource selection should follow a multiscale approach. Both the relative availability of habitat types as well as individual variation in home range size should be accounted for in order to disentangle the complex mechanisms that contribute to shape patterns of resource selection in animals.
\end{abstract}

The patterns of habitat selection are assumed to represent a behavioural adjustment to heterogeneous distribution of resources (Fretwell and Lucas 1969, Holt 1985, Boyce and McDonald 1999). Optimal foraging theory (reviewed in Stephens and Krebs 1986) suggests that the value in terms of fitness gain of a resource is to some extent a function of its availability (Charnov 1976), whereas the availability of resources within a habitat type influences the time spent by an individual in that habitat type (Brown 1988). A central assumption of this theory is the presence of tradeoffs between different constraints that affects the fitness return of the behavioural decision (McNamara and Houston 1994). One example is the choice to spend time in open areas with high forage abundance or quality versus hiding in closed areas that offer protective cover (Mysterud and Ims 1998, Mysterud and Østbye 1999, Dussault et al. 2005a). Furthermore, the selection for high-quality foraging patches can depend on local density of animals (Rosenzweig 1991). This is related to the hypothesis of ideal free distribution
(IFD), which suggests that individuals must increase the utilisation of lower-quality patches at higher population densities to maximise their fitness (Fretwell and Lucas 1969). However, most plant-herbivore systems experience dynamic resource levels through space and time (Jones et al. 2006), and feed-back mechanisms between herbivores and their food resources (Danell et al. 1985, Bergström and Danell 1987), which reduce the applicability of this theory (Kohlmann and Risenhoover 1997, Jones et al. 2006, but see Kausrud et al. 2006, Mobæk et al. 2009).

One fundamental assumption in many habitat selection analyses is that animals use a constant proportion of a habitat type independently of its proportional availability (i.e. a constant selection ratio, Aebischer et al. 1993, Manly et al. 2002). This is embedded in the assumption of a constant selection ratio for each habitat type in most resource selection functions analyses (RSF; Manly et al. 2002). However, the relative use of a habitat type can change with changing availability, a phenomenon termed 
"functional response in habitat selection" by Mysterud and Ims (1998). Such functional response may for instance occur as a result of switching, e.g. when animals select for a specific habitat or resource when availability is above some threshold, or due to changes in tradeoffs between resource types with changing availability. There are evidences that the availability of resources influence the degree of selection for that resource (Mysterud and Ims 1998, Mysterud and Østbye 1999, Osko et al. 2004, Godvik et al. 2009, Hansen et al. 2009a, b). However, because large variation in home range size among conspecifics in a population is common (Börger et al. 2006a), there can also be large variation in the absolute availability of resources that is not reflected in the relative availability unless the variation in home range size is linked to resource availability. Thus, the influence of relative availability of resources on habitat selection should also be related to individual home range size in order to achieve a better understanding of the functional response in habitat selection.

The spatial scale may have a great influence on the decision making processes and observed behaviour of animals (Johnson et al. 2002), and have recently received increased attention (Senft et al. 1987, Dussault et al. 2005a, 2006, Månsson et al. 2007, Zweifel-Schielly et al. 2009). Because resource use decisions can be based on different criteria at different spatial scales (Senft et al. 1987, Månsson et al. 2007, Kittle et al. 2008), one can also expect contrasting habitat selection between scales (Johnson et al. 2001). It is proposed that factors with highest fitness impact should influence most on habitat selection at the larger scale (Senft et al. 1987, Dussault et al. 2005b). For example, habitat selection at the landscape scale could seek to minimise predation risk if this is the most important limiting factor for individual fitness (Schaefer and Messier 1995, Johnson et al. 2001, Dussault et al. 2005b), whereas at a finer scale, forage optimisation is often the driving mechanism of habitat selection (Schaefer and Messier 1995, Johnson et al. 2001, 2002, Månsson et al. 2007).

In this paper, we examined individual habitat selection during summer by moose Alces alces on the island of Vega, Norway. Moose typically face a trade-off between the time spent in different habitat types providing resources required for diverse activities (White and Berger 2001). During summer, they must forage intensively to meet the energetic requirements associated with lactation, antler growth, body growth and replenishment of body reserves before the rutting season and forthcoming winter (Schwartz et al. 1987). At this time of the year, moose also need to seek protective cover as an anti-predator strategy, particularly females with calf/calves at heel (White and Berger 2001), or for thermoregulation (Dussault et al. 2004). The differences in net gain and resource requirements between different categories of animals may cause habitat segregation (Miquelle et al. 1992) and different dietary functional response (Andersen and Sæther 1992), which we expect will be reflected in the selection for habitat types.

The development of mixed effects models has improved our ability to analyse individual variation in habitat selection by allowing inclusion of individuals as a random effect in RSFs (Gillies et al. 2006), and can also be used to test for functional response in habitat selection by including availability and home range size as covariates in the model.
Using this approach, we here analysed habitat selection at two spatial scales, the landscape scale (choice of home range) and home range scale (choice of habitat types within the home range; Johnson 1980). Following findings by Dussault et al. (2005b), we predicted that moose habitat selection at the landscape scale would seek to minimise predation risk through a preference for habitat types with protective cover and a low degree of human disturbance. However, the moose on Vega experience no predation apart from hunting during autumn, and the temperature is generally within the critical range of thermoregulation during summer. The lack of direct predation risk may weaken the scale-dependency in habitat selection because indirect risk (e.g. human presence) is more predictable and can be incorporated in the resource selection decisions (Kittle et al. 2008). Thus, we expected that predation risk was less relevant in our study system, and predicted that moose select habitats primarily as a function of forage abundance and quality (Peek 1997). Females though would still be expected to exhibit a preference for protective cover at both spatial scales since virtually all adult females have calf or calves at heel (Tremblay et al. 2007). At the home range scale, we investigated the hypothesis of functional response in habitat selection by relating individual variation in habitat selection to home range size and the relative availability of habitat types. We expected the degree of selectivity for preferred habitat types to be higher among individuals with low availability of these habitat types compared to individuals with a high availability. Finally, we expected the selection for preferred habitat to be weaker among individuals experiencing high moose density (Fretwell and Lucas 1969, Rosenzweig 1991).

\section{Materials and methods}

\section{Study area and moose population}

We obtained data from the moose population at the island of Vega $\left(119 \mathrm{~km}^{2}\right)$ in Nordland county, northern Norway (Fig. 1). The study area was defined as the main island as well as smaller associated islands accessible to moose. A mosaic of vegetation types, dominated by moorland (32\%), forests (15\%) (mainly Norway spruce Picea abies, Scots pine Pinus sylvestris and birch Betula pendula and B. pubescens), marshes (12\%), farmland (13\%) and grassland $(8 \%)$, characterise the relatively flat landscape of the island (Angeloff et al. 2004). 75\% of the island area is below $80 \mathrm{~m}$ a.s.l. The climate is oceanic with a mean temperature of $13^{\circ} \mathrm{C} \pm 3 \mathrm{SD}$ in summer (June-August) and $0.5^{\circ} \mathrm{C} \pm 4 \mathrm{SD}$ in winter (December-March) during 1992-2002 (Angeloff et al. 2004). Mean annual precipitation reach $239 \mathrm{~mm}$ in summer and $394 \mathrm{~mm}$ in winter (21\% as snow).

The current moose population on Vega was founded in 1985, when three animals swam across from the mainland. Over the course of the study, the number of moose in winter varied from 25 to 40 individuals. Hunting is the main source of mortality (Sæther et al. 2003). As part of another study, the structure of the population was manipulated by leaving only young $(\leq 2.5$ year) males as potential breeders in 1995 and 1996 and reducing the adult sex ratio in the population to about 25\% males from 1997 to 1999 


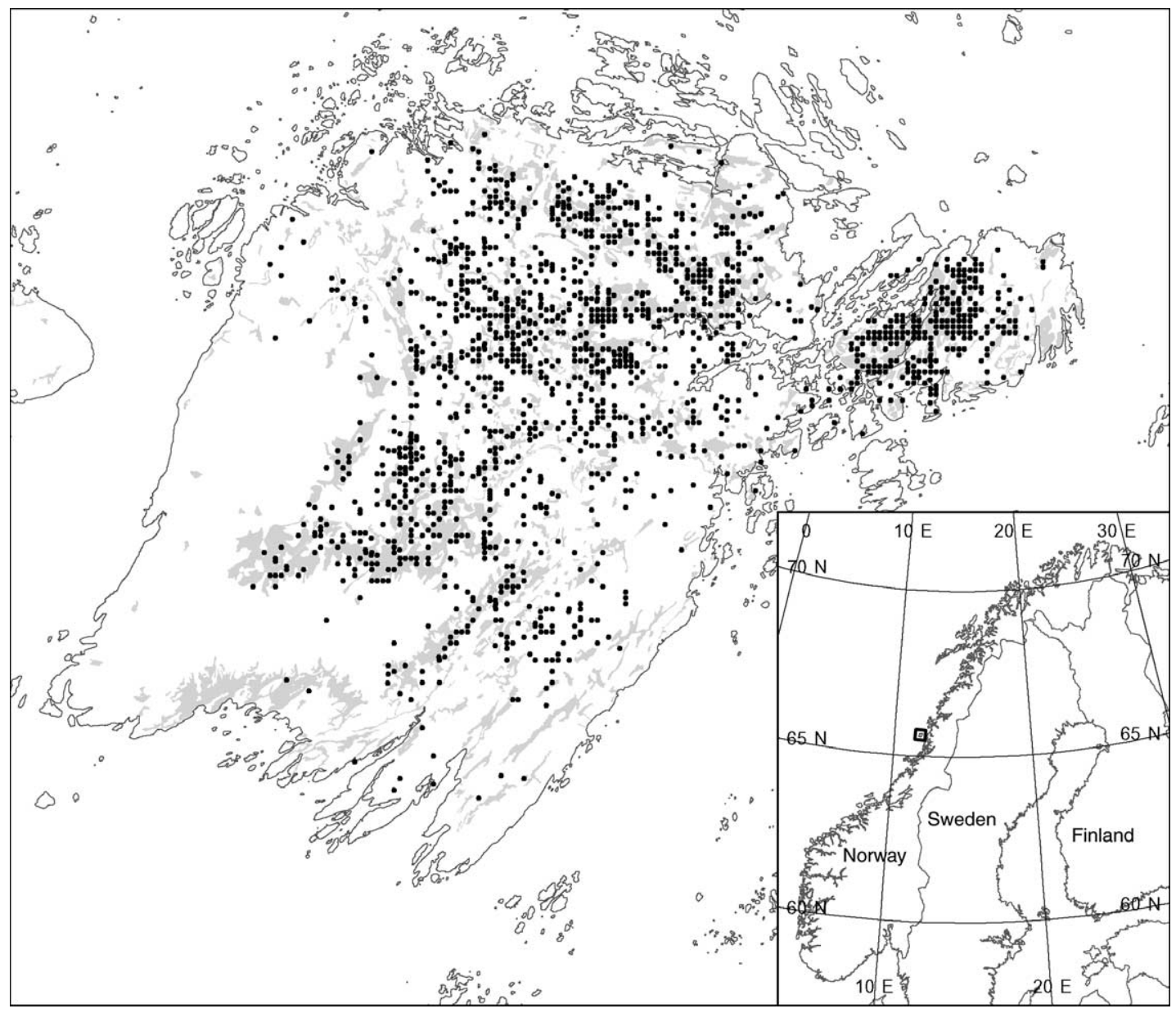

Figure 1. Localisation of the study area: the island of Vega off the Norwegian coast. Black dots indicate telemetry fixes of 66 moose from 1993 to 1997. Areas that provide cover (forest) are shown in gray shading. In the west and south-western part of the island, the mountain Trollvasstinden extends above the tree-line (to about 800 m.a.s.l.). Most of the mountain area is above the tree line, rocky and steep, and usually not utilised by moose.

(Sæther et al. 2003, 2004). The population of domestic livestock at the time of the study was estimated to 3110 cattle and 500 sheep (Anon. 2001). The livestock was kept indoors during winter, and the sheep and ca 500 cattle were grazing in outlying grazing fields during summer, mainly in association with agriculture areas.

\section{Moose and habitat data}

In 1992 and 1993, we captured all individuals in the population ( $\mathrm{n}=6$ males, 11 females and 8 calves) and marked them with VHF radio-collars (see Sæther et al. 2004 for details on the capture protocol). In the subsequent years, we captured and marked all calves that survived the previous hunting season as well as immigrants, and recaptured animals with malfunctioning transmitters or lost collars. Age of individuals not born in the course of the study was estimated by counting cementum annuli of incisors of shot animals (Rolandsen et al. 2008). Manipulations comply with the current laws adopted by the Norwegian government. Moose were relocated by radiotriangulation from the ground throughout the year using a UTM grid with a $100-\mathrm{m}$ resolution. The relocations were done during day and evening. Some noise in the fixes was introduced by a change in datum (ED1950 to WGS84) early in the study without our knowledge at the time, causing a shift of ca $200 \mathrm{~m}$. However, as the map sources used in the field work were updated frequently, we believe only a small proportion of the points have this systematic error. We performed homing on a subset of fixes to confirm the precision of the triangulated fixes. This was done during calving when females were approached on foot to determine calving status. At this stage females are relatively immobile by the newborn and precision can be determined by measuring the deviation between triangulated fixes and actual position of the female. The small scale and high density of roads in the study area ensured that most triangulate fixes were taken from positions $<300 \mathrm{~m}$ from the moose, providing a triangulate fix precision of less than $\pm 100 \mathrm{~m}$, on average.

We restricted the study period to the post-calving period (15 June, median date of birth on Vega was 30 May with $90 \%$ of births between 19 May and 22 June, Solberg unpubl.) until the start of the hunting season (25 September). We excluded fixes that were in the ocean and $>100 \mathrm{~m}$ from land $(\mathrm{n}=12)$. Fixes that were located in the ocean but closer than $100 \mathrm{~m}$ from land were assigned habitat class from the closest habitat patch. Moose were 
classified as yearlings ( $1 \mathrm{yr}$ old at start of summer) or adults ( $2 \mathrm{yr}$ or older at start of summer).

We delineated annual summer home ranges (100\% minimum convex polygon, MCP) for moose with at least 10 fixes during a study season. In order to achieve a fairly systematic temporal distribution of the observations, we used (for each individual each year) a subset of fixes with at least $2 \mathrm{~d}$ and a maximum of $30 \mathrm{~d}$ interval between successive fixes. A total of 117 summer home ranges of 66 individual moose of known age and sex based on 2145 radio-telemetry fixes were included in the analyses. We chose $100 \% \mathrm{MCP}$ instead of alternative home range estimators (e.g. kernel density; KD) following Gillies et al. (2006). There are considerations with both home range estimators (Girard et al. 2002, Hemson et al. 2005, Börger et al. 2006b, Nilsen et al. 2008). We chose to use MCP because we wanted to include excursions made by moose and thus delineate a general area in which moose would be familiar with the distribution of habitat types. Moreover, we wanted to use the home range both as a measure of use (at the landscape scale) and availability (at the home range scale). Preliminary analyses showed that the KD home range (95\% fixed kernel) tended to match the patch scale in the definition of availability, possibly confounding the two spatial scales we focused on.

As a measure of local animal density experienced by each individual moose a given summer, we overlaid all home ranges for that year. Each individual home range was assigned the sum of overlapping home ranges, weighted by their proportional overlap. We then, for each individual home range, calculated the mean number of home ranges inside it. To remove any effects of difference in sampling effort between years (number of moose included per year in the study), we scaled the values to range between 0 and 1 within year.

The distribution of habitat types on the island was based on a detailed vegetation survey (1:50000 scale) of the island, performed in 2000 and 2003 (Angeloff et al. 2004). The digital habitat data consisted of polygons, where the accuracy of the habitat borders were ca $5 \mathrm{~m}$ (smallest distinct habitat patch ca $1000 \mathrm{~m}^{2}$ ). The habitat classification was based on an expert-evaluation of the grazing value for cattle of each habitat type (a total of 41 habitat types classified into poor, fair and good grazing area, Table 1, Angeloff et al. 2004). Although moose and cattle differ in diet and feeding behaviour, the broad habitat classifications based on grazing value for cattle appeared to provide a fair classification also for moose during summer, particularly for habitats located in forests (Table 1). In general, the different habitat types increased in grazing value with increasing soil nutrient and to some extent moisture (Larsson and Rekdal 2000). Such conditions provide better growing conditions for bilberry Vaccinium myrtillus and large forbs (Larsson et al. 1994), which during summer are preferred over deciduous leaves and woody browse as foraging species for moose (Sæther et al. 1992). Moreover, the density of preferred deciduous trees and bushes such as birch Betula pubescens and willows Salix sp., increased with habitat grazing value when the habitat type was located in forests (Table 1), which also suggest a positive relationship between the classification of grazing value for cattle and the value as moose foraging areas of a habitat type. Accordingly, we classified the habitats by their grazing value for cattle as well as their level of forest cover (forested or open) to a total of nine different habitat types (Table 1). In addition, we estimated the level of human impact using the density of buildings and roads within habitat types (Table 1). Four habitat types were particularly associated with humans: good open, good forest, agricultural and unproductive areas (Table 1).

At the landscape scale availability was defined as the proportion coverage of the habitat types within the entire study area (Fig. 1) and utilisation was defined as the habitat composition within the $100 \%$ MCP summer home ranges. At the home range scale availability was restricted to the $100 \%$ MCP summer home ranges, whereas the habitat types at the fixes were considered as utilised habitat types.

\section{Habitat selection at the landscape scale}

We analysed moose habitat selection at the landscape scale using selection ratios ( $S R$, Manly et al. 2002), i.e. the proportion of habitat type $j$ utilised (proportion of habitat type $j$ inside the home range of a moose) in relation to the

Table 1. Habitat types as classified by their grazing value and cover for moose on Vega Island. Area represents availability of the given habitat type on the island. An asterisk indicates high human impact in the habitat type, based on the density of roads and buildings.

\begin{tabular}{|c|c|c|c|c|c|c|}
\hline Grazing value & Cover & Description & $\begin{array}{l}\text { Area } \\
\left(\mathrm{km}^{2}\right)\end{array}$ & $\begin{array}{l}\% \text { of total } \\
\text { area }\end{array}$ & $\begin{array}{l}\text { Buildings } \\
\mathrm{km}^{-2}\end{array}$ & $\begin{array}{c}\mathrm{km} \text { roads } \\
\mathrm{km}^{-2}\end{array}$ \\
\hline Poor & Open & $\begin{array}{l}\text { Mountain ridge, tundra, wet alpine meadows, } \\
\text { shrub bogs and heather moors. }\end{array}$ & 56.1 & 43.4 & 1.0 & 0.4 \\
\hline Poor & Forest & $\begin{array}{l}\text { Forests (mainly pine) with lichen or heather } \\
\text { as ground cover, poor wet forest. }\end{array}$ & 8.8 & 6.8 & 5.1 & 1.0 \\
\hline Fair & Open & $\begin{array}{l}\text { Snow bed, alpine meadows, } \\
\text { grassy bogs and swamps. }\end{array}$ & 19.4 & 15.0 & 1.7 & 0.8 \\
\hline Fair & Forest & $\begin{array}{l}\text { Forest with bilberry as ground cover, } \\
\text { swampy forest, pasture pine forest. }\end{array}$ & 4.5 & 3.5 & 1.3 & 1.0 \\
\hline Good* & Open* & $\begin{array}{l}\text { Meadows, grazing pastures for livestock, } \\
\text { abandoned agricultural fields. }\end{array}$ & 7.6 & 5.9 & 36.4 & 3.6 \\
\hline Good* & Forest* & $\begin{array}{l}\text { Pasture birch forest, alder forest, rich wet } \\
\text { forest. }\end{array}$ & 6.3 & 4.9 & 15.8 & 2.4 \\
\hline Agricultural* & Open* & Agricultural fields for grass production. & 13.1 & 10.1 & 12.9 & 4.4 \\
\hline Lakes & Open & Open water bodies (lakes and rivers). & 2.6 & 2.0 & 0.0 & 0.1 \\
\hline $\begin{array}{l}\text { Unproductive } \\
\text { areas* }\end{array}$ & Open* & $\begin{array}{l}\text { Built-up and developed areas, bare rock, } \\
\text { gravels and boulders. }\end{array}$ & 11.0 & 8.5 & 18.7 & 1.4 \\
\hline
\end{tabular}


proportion of habitat type $j$ in the available area. Because the distribution of the values was right-skewed, we ln-transformed the selection ratios, adding 0.001 to the proportion used to allow calculation of $S R$ for non-used habitat types. Negative $S R_{j}$ indicates avoidance of habitat type $j$, while positive $S R_{j}$ indicates a selection for habitat type $j$.

We evaluated the importance of habitat type, demographic group and home range size on $S R$ by including these variables together with the full set of possible interactions in a linear mixed model with year and moose individual added as random factors. By including both as random components in the models, we accounted for interdependency in observations within year as well as repeated observations of the same individual. Individuals were grouped to four demographic classes; female yearlings, female adults, male yearlings and male adults. We used chisquared tests based on differences in log-likelihood and number of estimated parameters between two candidate models (Crawley 2007) to maximise the model fit relative to the number of estimated parameters. Thus, we compared a model against a simplified model (removing one term from the more complex model), and kept the complex model if this had a significantly higher fit. If a model included an interaction, the lower-grade interactions and main effects were always retained in the model. Because the effects of demographic group and home range size without the interaction with habitat type make no sense with respect to the selection ratios, models with one of these variables always included the interaction with habitat type.

\section{Habitat selection at the home range scale}

At the home range scale, we used fixes as measure of utilised habitat. The probability of use of habitat types can be considered as a multinomial distribution that can be modelled as a Poisson log-linear model with random effects, belonging to the class of generalised linear mixed models (Chen and Kuo 2001). Accordingly, we could model the number of observations from each moose inside a habitat type $j$ using a Poisson log-linear model with random intercepts (moose individual as random factor). Random use of habitat types inside the home range provided the expected number of observations inside habitat type $j=$ total number of observations $\times$ proportion of habitat type $j$ available. We therefore added $\ln$ (proportion of habitat type $j$ in the home range) as an offset variable (Venables and Ripley 2002) to account for this expected linear relationship in the generalised linear mixed models. After accounting for the proportion with the offset, no selection for habitat type $j$ would be indicated by an estimate equal to the average number of points per habitat type from the annual set of moose observations. By subtracting the average annual number of points per habitat from the estimated selection parameters, selection for a habitat type is indicated by values above 0 , whereas avoidance is indicated by values below 0 . A null model (i.e. with intercept only in addition to the random terms and the offset variable) provided the estimate of the expected ln-number of points inside a habitat type of random size (estimated number of points $=\exp (2.89)=$ 17.99), accounting for the interdependence within year and individual. Selection for a habitat type would imply parameter estimates above this value. In the results 2.89 is subtracted from the estimates to indicate selection and avoidance with values above and below 0 , respectively. Individual moose and year were added as random factors in the same way as in the analysis at the landscape scale.

We examined the importance of habitat type and the individual characteristics (home range size, availability and local density) for habitat selection within home ranges. Because we found only limited effects of demographic groups on the habitat selection at the home range scale (see Results, Habitat selection at the home range scale), and to avoid over-parameterisation of the analyses, we excluded demographic group from the final model selection procedure. The inclusion of relative availability and home range size allowed us to test whether any conditional dependence in habitat selection was due to relative availability, or to the absolute area of the habitat types. Local density was added together with its interaction with habitat type. We followed a similar approach as for the landscape scale regarding model simplification, specifying a set of valid models (Table 2).

All models, both at the landscape and home range scale, were fitted with the lmer-function in the lme4 package (Bates et al. 2008) in $\mathrm{R}$ for windows version 2.8.1 (R Development Core Team 2008). Effects of explanatory variables were estimated with posterior resampling $(\mathrm{n}=$ $10000)$ of the parameter estimates from the fitted model, with significance achieved if the 95\% quantiles (95\% confidence interval) did not include zero.

\section{Results}

\section{Home range size}

The average summer home range size was $17.4 \mathrm{~km}^{2} \pm 9.8$ SD, based on an average of 18.2 \pm 2.9 SD telemetry fixes (number of fixes for adult males: $19.3 \pm 2.5 \mathrm{SD}$, adult females: $18.3 \pm 2.4 \mathrm{SD}$, yearling male: $17.0 \pm 3.4 \mathrm{SD}$, yearling female: $18.3 \pm 2.4 \mathrm{SD})$. The home range size did not increase significantly with number of telemetry fixes (estimate of increase in home range size $\left(\mathrm{km}^{2}\right)$ per fix: 0.16 , 95\% CI: $-0.40 ; 0.89)$, even after accounting for age and sex $(0.11,95 \% \mathrm{CI}:-0.48 ; 0.73)$. The home range size differed significantly between some of the sex and ageclasses (adult female vs adult male: $\mathrm{t}=-6.29$, $\mathrm{DF}=40.69$, $\mathrm{p}<0.001$, yearling female vs yearling male: $\mathrm{t}=-0.01$, $\mathrm{DF}=35.91, \mathrm{p}=0.995$, yearling female vs adult female: $\mathrm{t}=$ $2.43, \mathrm{DF}=25.42, \mathrm{p}=0.023$, yearling male vs adult male: $\mathrm{t}=-2.39, \quad \mathrm{DF}=37.71, \mathrm{p}=0.022)$. Adult males had larger home ranges $\left(24.6 \mathrm{~km}^{2} \pm 9.3 \mathrm{SE}, \mathrm{n}=26\right)$ than yearlings (females; $18.0 \mathrm{~km}^{2} \pm 10.4 \mathrm{SE}, \mathrm{n}=20$, males; $\left.18.0 \mathrm{~km}^{2} \pm 8.9 \mathrm{SE}, \mathrm{n}=18\right)$ and adult females $\left(11.9 \mathrm{~km}^{2} \pm\right.$ 6.7 SE, $\mathrm{n}=41$ home ranges). The home range size was not significantly related to the local density experienced by the individual moose neither when looking for age- and sexspecific differences in the relationship (interaction between demographic group and local density: $\chi^{2}=3.05, \mathrm{DF}=3$, $\mathrm{p}=0.384$ ) nor as a main effect accounting for demographic differences in the home range size $\left(\chi^{2}=3.05, \mathrm{DF}=1\right.$, $\mathrm{p}=0.294)$. 
Table 2. The Log-likelihood and number of estimated parameters $(K)$ that were the basis for the model reduction regarding the effect of relative availability (RA), home range size (HR size) and local density on the habitat selection at the home range scale among moose at Vega. An X indicates that the variable was included in the candidate model. An interaction between two variables $\mathrm{A}$ and $\mathrm{B}$ are $\operatorname{denoted} \mathrm{A} \times \mathrm{B}$ and always contain the main effects of $A$ and $B$. The model in bold was the model that gave the best fit based on the principle of parsimony.

\begin{tabular}{|c|c|c|c|c|c|c|c|c|c|}
\hline Model & $\begin{array}{c}\text { Habitat } \\
\text { type }\end{array}$ & RA & $\begin{array}{c}\text { Habitat type } \\
\times \mathrm{RA}\end{array}$ & $\begin{array}{l}\text { Habitat type } \\
\times \text { HR size }\end{array}$ & $\begin{aligned} & \text { RA } \\
\times & \text { HR size }\end{aligned}$ & $\begin{array}{l}\text { Habitat type } \\
\times \text { HR size } \times \text { RA }\end{array}$ & $\begin{array}{l}\text { Local Density } \\
\times \text { Habitat type }\end{array}$ & Log-likelihood & $K$ \\
\hline 1 & $x$ & & & & & & & -549.90 & 11 \\
\hline 2 & $\mathrm{X}$ & $X$ & & & & & & -543.98 & 12 \\
\hline 3 & $X$ & $X$ & $X$ & & & & & -539.58 & 20 \\
\hline 4 & $X$ & & & $X$ & & & & -541.29 & 20 \\
\hline 5 & $X$ & $\mathbf{X}$ & & $X$ & & & & -535.20 & 21 \\
\hline 6 & $X$ & $X$ & & $X$ & $x$ & & & -535.20 & 22 \\
\hline 7 & $X$ & $X$ & $X$ & $X$ & & & & -528.77 & 29 \\
\hline 8 & $X$ & $X$ & 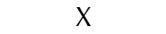 & $X$ & 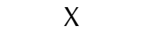 & & & -528.77 & 30 \\
\hline 9 & $X$ & $X$ & $X$ & $X$ & $X$ & $X$ & & -526.04 & 38 \\
\hline 10 & $X$ & & & & & & $X$ & -545.75 & 20 \\
\hline 11 & $x$ & $\mathrm{X}$ & & & & & $X$ & -538.91 & 21 \\
\hline 12 & $X$ & $X$ & $x$ & & & & $x$ & -533.70 & 29 \\
\hline 13 & $X$ & & & $X$ & & & $X$ & -537.86 & 29 \\
\hline 14 & $X$ & $X$ & & $X$ & & & $x$ & -530.39 & 30 \\
\hline 15 & $X$ & $X$ & & $X$ & $x$ & & $X$ & -530.39 & 31 \\
\hline 16 & $X$ & $X$ & $X$ & $X$ & & & $X$ & -523.57 & 38 \\
\hline 17 & $X$ & $X$ & $X$ & $X$ & 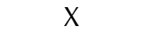 & & 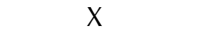 & -523.57 & 39 \\
\hline 18 & $X$ & $X$ & X & $X$ & $X$ & $\mathrm{X}$ & X & -521.43 & 47 \\
\hline
\end{tabular}

\section{Habitat selection at the landscape scale}

The likelihood ratio tests suggested that a model with the full three-way interaction (demographic group $\times$ habitat type $\times$ home range size) was not significantly better than a model with habitat type and its two-way interactions with demographic group and home range size $\left(\chi^{2}=24.93, \mathrm{DF}=\right.$ $27, \mathrm{p}=0.579)$. This model was significantly better than the model with only the interaction habitat type $\times$ home range size $\left(\chi^{2}=69.83, \mathrm{DF}=27, \mathrm{p}<0.001\right)$, as well as compared to a model with demographic group $\times$ habitat type alone $\left(\chi^{2}=141.07, \mathrm{DF}=9, \mathrm{p}<0.001\right)$. Accordingly, the model with best fit suggested that selection for habitat types depended on sex and age (Fig. 2), and was related to individual home range size (Fig. 3). The differences between demographic groups in the preference and avoidance for habitat types were rather small for most habitat types, as they mainly occurred as differences in the degree of selection (not the direction; Fig. 2). In general, moose selected for poor forest range, good forest range and agricultural fields, and against poor open range, fair forest range, good open range and unproductive areas (Fig. 2). Thus, there was no general avoidance of habitats associated with human on the landscape scale (Fig. 2). The relationship between home range size and habitat selection differed between habitat types (Fig. 3), being significant positive for agricultural fields and unproductive areas (Fig. 3), and negative for poor forest range and good forest range (Fig. 3).

\section{Habitat selection at the home range scale}

The overall habitat selection at the home range scale (all age- and sex-classes pooled, see below) differed considerably from the landscape scale (Fig. 2). In particular, moose selected for fair open range and fair forest range at the home range scale, whereas at the landscape scale moose avoided or showed no selection for these habitat types. Moreover, moose showed no selection for good forest range and avoided agricultural fields, i.e. there was no significant

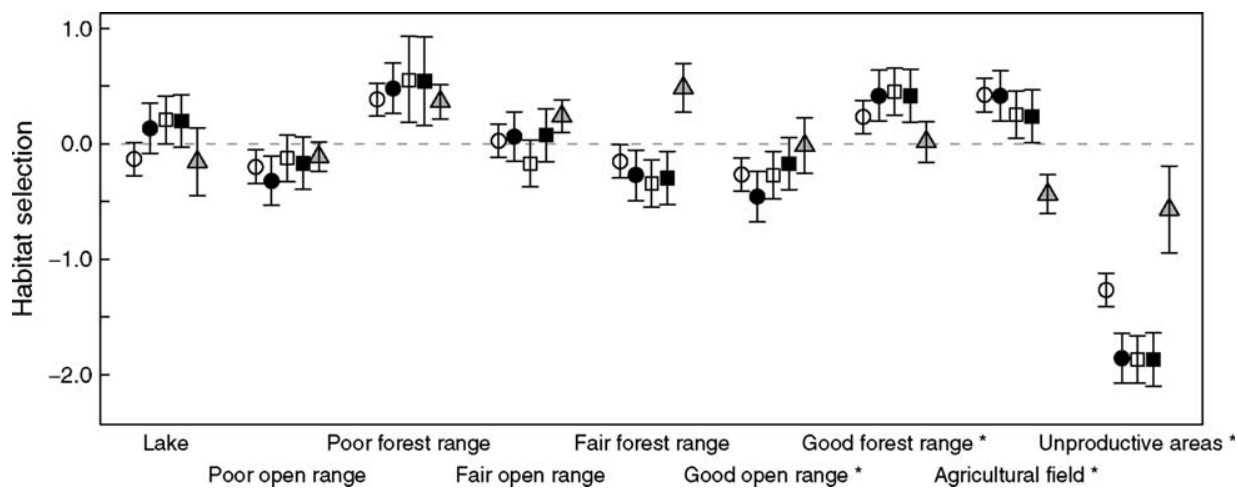

Figure 2. Habitat selection of moose at the landscape scale at Vega for adult females (open circles), yearling females (filled circles), adult males (open squares) and yearling males (filled squares). In addition, the overall habitat selection at the home range scale is shown as grey triangles. The dashed line indicates where the proportion used is similar to the proportion available. Values above zero indicate preference, whereas values below zero indicate avoidance. Bars represent $95 \%$ confidence interval of the parameter estimates. An asterisk behind the habitat type indicates high human impact. The habitat types are described in Table 1. 


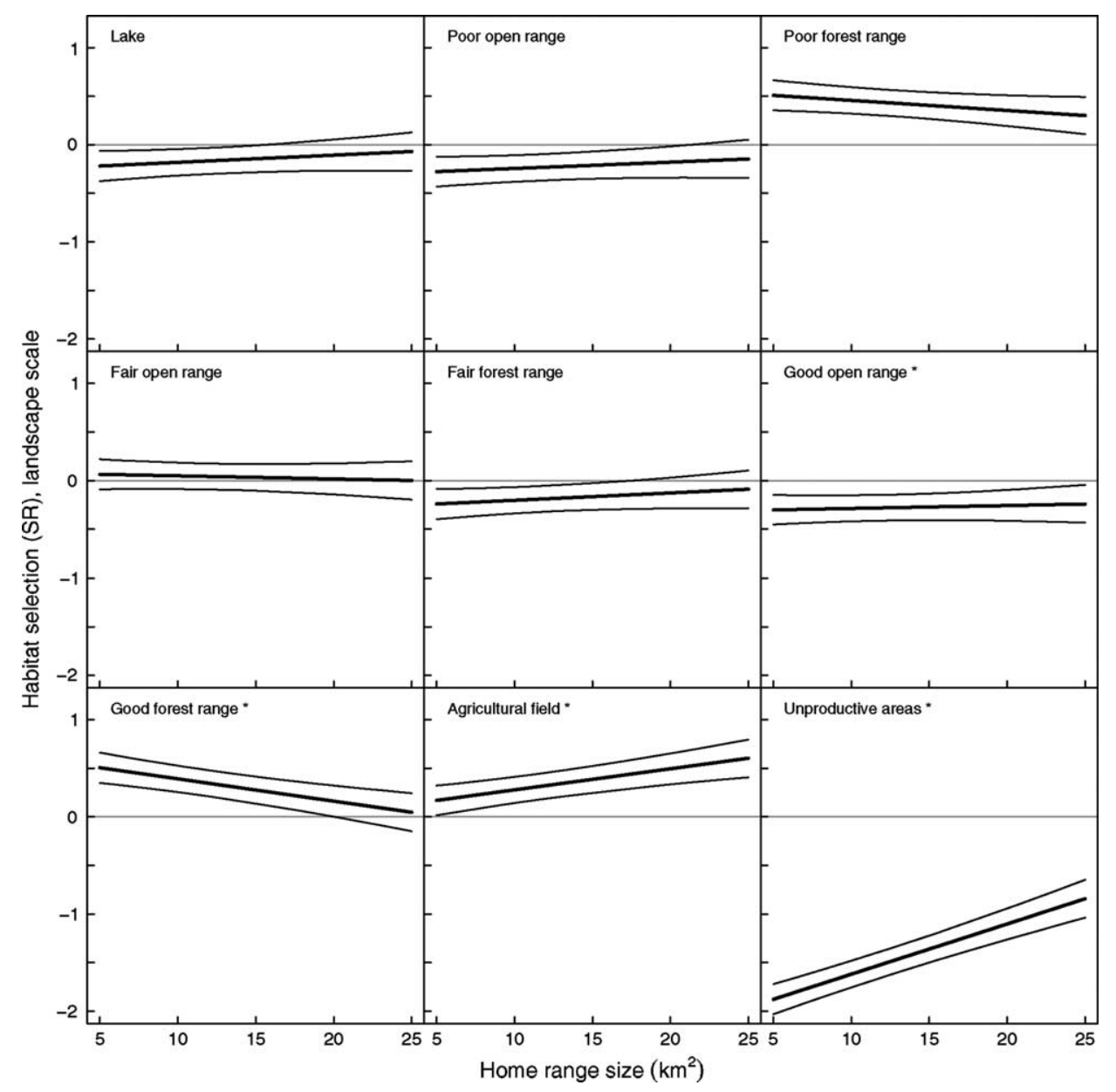

Figure 3. The relationship between home range size $\left(\mathrm{km}^{2}\right)$ of moose at Vega and the selection ratio (SR) at the landscape scale. The thin lines represent $95 \%$ confidence interval. Values above 0 indicate selection for the habitat type, whereas values below 0 indicate avoidance. The estimated effects for the different habitat types are shown for adult females only. For the additive effect of age and sex on the SR, see Fig. 2. An asterisk behind the habitat type indicates high human impact. The habitat types are described in Table 1.

preference for habitat types associated with high human impact at the home range scale (Fig. 2). In contrast, both good forest range and agricultural fields were selected for at the landscape scale (Fig. 2).

The model with habitat type had a significantly better fit than a model with intercept only $\left(\chi^{2}=157.44, \mathrm{DF}=8\right.$, $\mathrm{p}<0.001)$. However, there was little support for any ageor sex-effect on the habitat selection at the home range scale. The change in fit was not significant when adding the interaction between habitat type and demographic group compared to a model with habitat type only $\left(\chi^{2}=22.29\right.$, $\mathrm{DF}=27, \mathrm{p}=0.723$ ). Moreover, demographic group had no significant influence on the impact of the other explanatory variables on habitat selection (all $\mathrm{p}>0.537$ ). We then evaluated the importance of home range size and relative availability on the selection of the different habitat types. The model reduction procedure (see Table 2 for details) suggested that a model with the main effect of relative availability as well as the interaction between home range size and habitat type was most parsimonious (model nr 5 in Table 2). Adding other two-way interactions or the full three-way interaction to this model did not increase the fit significantly (all $p>0.117$ ). Local density (with its interaction with habitat type) did not increase the fit of the model significantly $\left(\chi^{2}=9.62, \mathrm{DF}=9, \mathrm{p}=0.382\right)$. Moreover, model 5 was significantly better than any simplification of the model (against model 1: $\chi^{2}=29.39$, $\mathrm{DF}=10, \mathrm{p}=0.001$; against model $2: \chi^{2}=17.55, \mathrm{DF}=9$, $\mathrm{p}=0.041 ;$ against model $4: \chi^{2}=12.18, \mathrm{DF}=1, \mathrm{p}<$ 0.001 ). According to model 5 (Table 2), the overall habitat selection differed between habitat types (Fig. 2), but home range size also influenced habitat selection, and this relationship differed between habitat types. The 95\% confidence intervals suggested that the relationships between home range size and selection for fair forest and good open range were significantly positive (Fig. 4), and differed from the more negative relationships for lake, agriculture and unproductive areas (Fig. 4). Finally, there was an overall negative association between the relative availability and degree of habitat selection (beta $=-1.30,95 \%$ CI: $-2.02 ;-0.54)$, suggesting an overall negative functional response in habitat selection with availability.

\section{Discussion}

Our results show that moose, regardless of age and sex, prefer habitat types that are associated with good foraging 


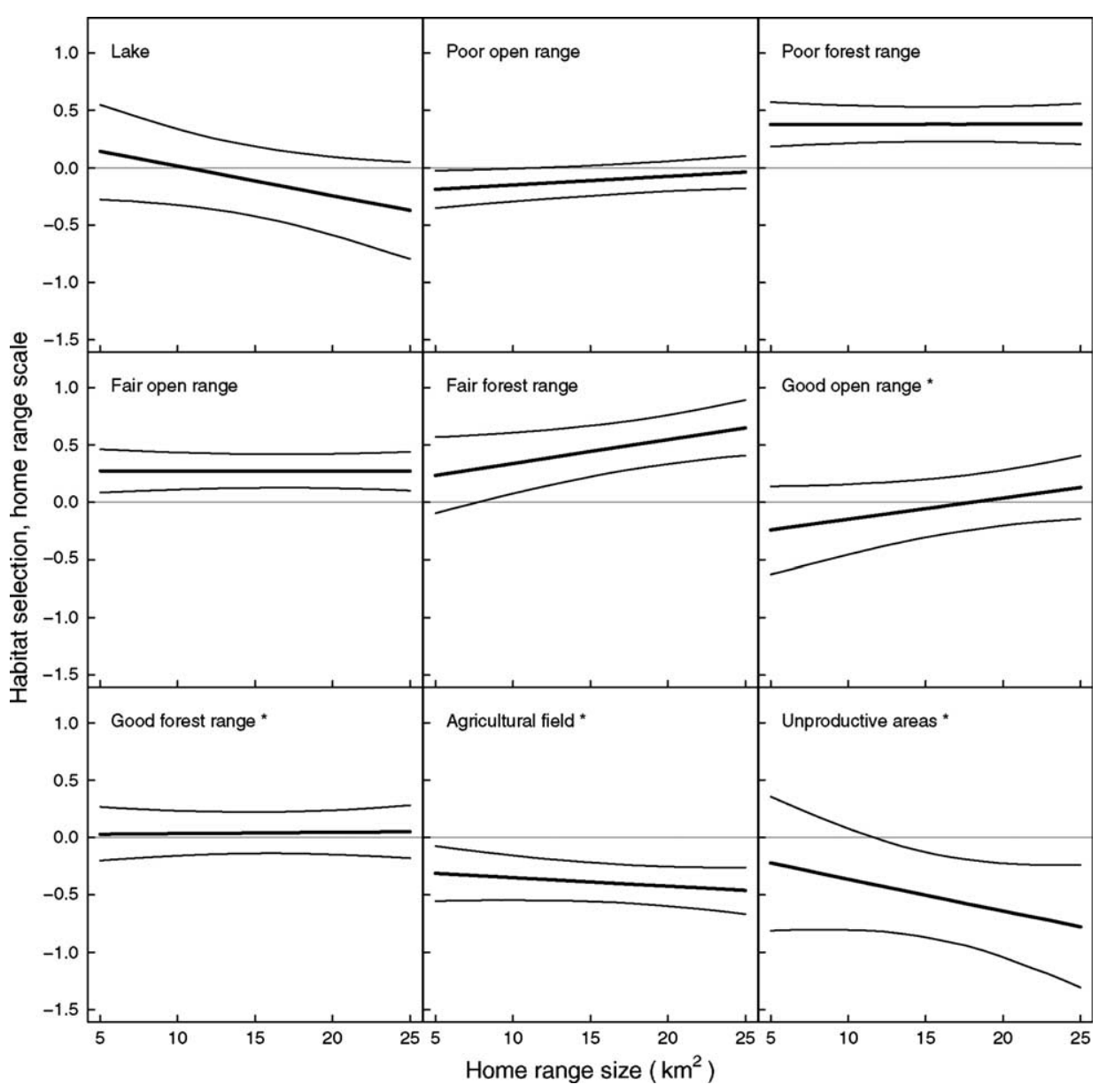

Figure 4. The relationship between home range size $\left(\mathrm{km}^{2}\right)$ of moose and selection for habitat types at the home range scale at Vega. The thin lines represent $95 \%$ confidence interval. Values above 0 indicate selection for the habitat type, whereas values below 0 indicate avoidance. An asterisk behind the habitat type indicates high human impact (Table 1).

conditions and cover, and are less associated with human disturbance (Fig. 2). Accordingly, habitat selection of moose at Vega seems to represent a balance between maximizing net energy gain and reducing the percieved mortality risk. However, the pattern of habitat selection depended on the spatial scale of the analyses. Moreover, the effects of individual home range characteristics (Table 2, Fig. 3, 4) indicate that habitat selection in moose can be described as a functional response to variation in availability of different habitat types.

At the landscape scale, the habitat selection by moose was related to both cover and forage quality, as reflected in the high selection ratios for poor and good forest ranges, as well as agriculture areas, whereas the habitat selection at the home range scale was towards fair forest range and against open areas neighbouring high human impact areas (Fig. 2 Table 1; Supplementary material). Thus, it seems that home range selection represents the outcome of a trade off between areas that provide cover, high quality forage and proximity to humans, whereas at the home range scale moose prefer areas with low perceived mortality risk. This contradicts with other studies on large herbivores suggesting that home ranges are selected to minimise predation risk (Johnson et al. 2001, Dussault et al. 2005b), whereas patches within the home range are selected to maximise forage intake (Johnson et al. 2001, Månsson et al. 2007).
On the other hand, it is also suggested that the high spatiotemporal predictability of indirect (perceived) predation risk (e.g. human presence) increases an animal's possibility to incorporate such information in their resource selection decision at the landscape scale (Kittle et al. 2008). In study systems with little direct predation risk (in our system there is no large carnivores and the hunting not yet started during summer), selection for good foraging conditions seems to be expressed already at the landscape level (Zweifel-Schielly et al. 2009). Accordingly, moose at Vega may be less concerned about risk minimisation compared to populations with higher direct predation risk (Dussault et al. 2005b, Kittle et al. 2008). Moreover, the small size of the island together with the spatial association between high-quality foraging areas and human impact may have favoured establishment of home ranges in proximity to humans.

An additional component that can influence the habitat use of wild ungulates is the presence of free-grazing livestock in areas available for foraging (Stewart et al. 2002, Mishra et al. 2004). In the study area, ca 500 cattle were grazing on rangeland during the summer season. Although we do not know much about the spatial distribution or habitat use of cattle during summer, it is reasonable to believe that cattle grazing occur mainly in areas associated with high human impact, both because of 
proximity to the farms and because much of the highquality areas are defined as grazing pastures (Table 1). Competitive exclusion of moose by cattle from good foraging areas close to human settlements can provide an additional explanation for the lack of moose preference for such areas at the home range scale. However, disentangling the effects of interspecific interference and human impact needs further research.

We found only minor differences in the habitat selection among the demographic groups, and only at the landscape scale. Differences between age groups or sex in the selection for habitat types can occur when there are differences in the net gain among the demographic groups, e.g. related to risk perception (Miquelle et al. 1992) or energetic requirements (Main 2008). A history of intensive harvesting on the island, particularly on males and juveniles (Sæther et al. 2003, 2004) can further increase demographic differences in habitat selection by creating sex-specific risk perception of particular habitat types. Such mechanisms can generate sexual segregation (Miquelle et al. 1992, Nikula et al. 2004), which in turn can result in sexual differences in the spatial distribution of available resources. However, we did not find any evidence for spatial segregation between male and female moose in our study system (Herfindal unpubl.). Moreover, the relatively confined island probably left few possibilities for demographic groups to segregate at a spatiotemporal scale detectable with our dataset. Indeed, as the age-sex effects on the habitat selection were rather small (Fig. 2), and did not occur at the home range scale, males and females seemed to be similarly constrained in their selection for habitat.

The habitat selection was related to individual home range size at both spatial scales (Fig. 3, 4), even after accounting for age and sex at the landscape scale and relative availability of habitat types at the home range scale. Thus, the change in selection with home range size seems to be a general result irrespective of age and sex of the moose. The larger home ranges included larger proportions of habitat types that were not selected for at the home range scale (Fig. 2, 3). Although this provides partial support for the prediction that low-quality home ranges should be larger in order to fulfil the energetic requirements of an individual (McNab 1963, Harestad and Bunnell 1979), it can not explain the significant positive and negative relationship between home range size and the selection for agricultural fields and poor forest ranges, respectively. This suggests that variation in home range size is not solely attributed to individual energy requirements and forage availability (Dussault et al. 2005b), but is probably also related to the distribution of protective cover and human presence (Tremblay et al. 2007). An alternative explanation is that habitat selection is related to different foraging habitats during day and night (Cederlund 1989, Godvik et al. 2009). Because our observations were mainly from day and evening, we may have failed to detect the complete pattern of the foraging component in the habitat selection.

The relationship between home range size and habitat selection at the landscape scale generated variation in the composition of habitat types among individual home ranges. The general pattern was that the utilisation of habitat types at the home range scale did not follow a 1:1 relationship with availability, which is evidence for a functional response in habitat selection (Mysterud and Ims 1998). Indeed, the relationship was weaker than 1:1 (indicated by the negative effect of relative availability on habitat selection) for all habitat types, suggesting that reduced availability of a habitat type generated stronger selectivity, irrespective of the value of that habitat type for the moose. However, because the relative availability was related to home range size, the functional response in habitat selection may not be revealed by the relative abundance only, but has to be evaluated together with home range size. One reason for this may be the relationship between habitat quality and home range size $(\mathrm{McNab}$ 1963, Harestad and Bunnell 1979). If a large home range is of poorer average quality, the relative availability of important habitat types is lower than in a high-quality home range, even if the absolute availability (area) does not differ between the two home ranges.

We did not find any effect of local animal density on moose selection for or avoidance of habitat types. This contradicts with the predictions from the ideal free distribution theory (Fretwell and Lucas 1969, Rosenzweig 1991) that increased density of animals should reduce the value of a patch in terms of fitness gains (McLoughlin et al. 2006), in turn leading to a reduction in preference for that habitat (Morris 2003). One reason for the lack of such effects can be that the moose population at Vega currently experience very favourable conditions, resulting in a high performance of individuals (Solberg et al. 2008) and a very high population growth rate (Sæther et al. 2007). Consequently, there are few indications on density effects on the populations. Moreover, density dependent resource selection is found to be most relevant at the finest scale (i.e. the diet choice at the foraging patch; Kausrud et al. 2006, Mobæk et al. 2009) and dependent on activity patterns (Mobæk et al. 2009). These are factors we could not account for in our analyses.

Based on individual moose data from a small isolated island, we have shown that ungulate habitat selection can depend on spatial scale and availability of resources. Even in the absence of predators and outside the hunting season, the moose on Vega try to make a compromise between protective cover, forage quality and avoidance of human presence in their habitat selection. Habitat selection within the home range is conditional on individual availability of resources. Mysterud and Ims (1998) considered the relative availability (proportion of habitat types available) in their exploration of functional response in habitat selection but also encouraged integration of home range size owing its effect on absolute availability. Accordingly, our results confirm that variation in home range size contributes to shape patterns of habitat selection at finer spatial scales. Habitat selection analyses that do not account for the possibility that selection depends on availability may fail to detect important habitat types and resources for a species. Inclusion of home range size in addition to relative availability of habitat types within an individual's home range provides an additional perspective to the patterns of resources selection in animals.

Acknowledgements - We are grateful to the Directorate for Nature Management, the County Governor in the County of Nordland and the Research Council of Norway for financial support. 
We thank B. Aleksandersen, O. A. Davidsen, J. M. Arnemo, Ø. Os and O. H. Bakke for help during field work, and M. Angeloff and Y. Rekdal at the Norwegian Forest and Landscape Inst. for providing the habitat data for Vega.

\section{References}

Aebischer, N. J. et al. 1993. Compositional analysis of habitat use from animal radio-tracking data. - Ecology 74: 1313-1325.

Andersen, R. and Sæther, B.-E. 1992. Functional response during winter of a herbivore, the moose, in relation to age and size. - Ecology 73: 542-550.

Angeloff, M. et al. 2004. Vegetasjon og skog på Vega. - Norsk institutt for jord- og skogkartlegging.

Anonymous 2001. Kommuneplan Vega Kommune: arealplan og handlingsprogram. - Vega kommune.

Bates, D. et al. 2008. lme4: linear mixed-effects models using S4 classes. $-\mathrm{R}$ package ver. 0.999375-28.

Bergström, R. and Danell, K. 1987. Effects of simulated winter browsing by moose on morphology and biomass of two birch species. - J. Ecol. 75: 533-544.

Börger, L. et al. 2006a. An integrated approach to identify spatiotemporal and individual-level determinants of animal home range size. - Am. Nat. 168: 471-485.

Börger, L. et al. 2006b. Effects of sampling regime on the mean and variance of home range size estimates. - J. Anim. Ecol. 75: 1393-1405.

Boyce, M. S. and McDonald, L. L. 1999. Relating populations to habitats using resource selection functions. - Trends Ecol. Evol. 14: 268-272.

Brown, J. S. 1988. Patch use as an indicator of habitat preference, predation risk, and competition. - Behav. Ecol. Sociobiol. 22: $37-47$.

Cederlund, G. 1989. Activity patterns in moose and roe deer in a north boreal forest. - Holarct. Ecol. 12: 39-45.

Charnov, E. L. 1976. Optimal foraging: the marginal value theorem. - Theor. Popul. Biol. 9: 129-136.

Chen, Z. and Kuo, L. 2001. A note on the estimation of the multinomial logit model with random effects. - Am. Stat. 55: 89-94.

Crawley, M. J. 2007. The R book. - Wiley.

Danell, K. et al. 1985. Interactions between browsing moose and two species of birch in Sweden. - Ecology 66: 1867-1878.

Dussault, C. et al. 2004. Behavioural responses of moose to thermal conditions in the boreal forest. - Écoscience 11: 321-328.

Dussault, C. et al. 2006. A habitat suitability index model to assess moose habitat selection at multiple spatial scales. - Can. J. For. Res. 36: 1097-1107.

Dussault, C. et al. 2005a. Space use of moose in relation to food availability. - Can. J. Zool. 83: 1431-1437.

Dussault, C. et al. 2005b. Linking moose habitat selection to limiting factors. - Ecography 28: 619-628.

Fretwell, S. D. and Lucas, H. L. 1969. On territorial behavior and other factors influencing habitat distribution in birds. - Acta Biotheor. 19: 16-36.

Gillies, C. S. et al. 2006. Application of random effects to the study of resource selection by animals. - J. Anim. Ecol. 75: 887-898.

Girard, I. et al. 2002. Effects of sampling effort based on GPS telemetry on home-range size estimations. - J. Wildl. Manage. 66: $1290-1300$.

Godvik, I. M. R. et al. 2009. Temporal scales, trade-offs, and functional responses in red deer habitat selection. - Ecology 90: 699-700.
Hansen, B. B. et al. 2009a. Winter habitat-space use in a large arctic herbivore facing contrasting forage abundance. - Polar Biol. 32: 971-984.

Hansen, B. B. et al. 2009b. Functional response in habitat selection and the tradeoffs between foraging niche components in a large herbivore. - Oikos 118: 859-872.

Harestad, A. S. and Bunnell, F. L. 1979. Home range and bodyweight - re-evaluation. - Ecology 60: 389-402.

Hemson, G. et al. 2005. Are kernels the mustard? Data from global positioning system (GPS) collars suggests problems for kernel home-range analyses with least-squares cross-validation. - J. Anim. Ecol. 74: 455-463.

Holt, R. D. 1985. Population-dynamics in 2-patch environments - some anomalous consequences of an optimal habitat distribution. - Theor. Popul. Biol. 28: 181-208.

Johnson, C. J. et al. 2001. Foraging across a variable landscape: behavioral decisions made by woodland caribou at multiple spatial scales. - Oecologia 127: 590-602.

Johnson, C. J. et al. 2002. A multiscale behavioral approach to understanding the movements of woodland caribou. - Ecol. Appl. 12: 1840-1860.

Johnson, D. H. 1980. The comparison of usage and availability measurements for evaluating resource preference. - Ecology 61: 65-71.

Jones, O. R. et al. 2006. Distribution of a naturally fluctuating ungulate population among heterogeneous plant communities: ideal and free? - J. Anim. Ecol. 75: 1387-1392.

Kausrud, K. et al. 2006. Density-dependent foraging behaviour of sheep on alpine pastures: effects of scale. - J. Zool. 270: 6371.

Kittle, A. M. et al. 2008. The scale-dependent impact of wolf predation risk on resource selection by three sympatric ungulates. - Oecologia 157: 163-175.

Kohlmann, S. G. and Risenhoover, K. L. 1997. White-tailed deer in a patchy environment: a test of the ideal-free-distribution theory. - J. Mammal. 78: 283-294.

Larsson, J. Y. and Rekdal, Y. 2000. Husdyrbeite i barskog. Vegetasjonstyper og beiteverdi. - NIJOS-rapport 9/2000.

Larsson, J. Y. et al. 1994. Barskogens vegetasjonstyper. - Landbruksforlaget.

Main, M. B. 2008. Reconciling competing ecological explanations for sexual segregation in ungulates. - Ecology 89: 693-704.

Manly, B. F. J. et al. 2002. Resource selection by animals. Statistical design and analysis for field studies. - Kluwer.

Månsson, J. et al. 2007. Moose browsing and forage availability: a scale-dependent relationship? - Can. J. Zool. 85: 372-380.

McLoughlin, P. D. et al. 2006. Lifetime reproductive success and density-dependent, multi-variable resource selection. - Proc. R. Soc. B 273: 1449-1454.

$\mathrm{McNab}, \mathrm{B} .1963$. Bioenergetics and determination of home range size. - Am. Nat. 97: 133-140.

McNamara, J. M. and Houston, A. I. 1994. The effect of a change in foraging options on intake rate and predation rate. - Am. Nat. 144: 978-1000.

Miquelle, D. et al. 1992. Sexual segregation in Alaskan moose. - Wildl. Monogr. 122: 1-57.

Mishra, C. et al. 2004. Competition between domestic livestock and wild bharal Pseudois nayaur in the Indian Trans-Himalaya. - J. Appl. Ecol. 41: 344-354.

Mobæk, R. et al. 2009. Density dependent and temporal variability in habitat selection by a large herbivore; an experimental approach. - Oikos 118: 209-218.

Morris, D. W. 2003. Toward an ecological synthesis: a case for habitat selection. - Oecologia 136: 1-13.

Mysterud, A. and Ims, R. A. 1998. Functional responses in habitat use: availability influences relative use in trade-off situations. - Ecology 79: 1435-1441. 
Mysterud, A. and Østbye, E. 1999. Cover as a habitat element for temperate ungulates: effects on habitat selection and demography. - Wildl. Soc. Bull. 27: 385-394.

Nikula, A. et al. 2004. Habitat selection of adult moose Alces alces at two spatial scales in central Finland. - Wildl. Biol. 10: $121-135$.

Nilsen, E. B. et al. 2008. Can minimum convex polygon home ranges be used to draw biological meaningful conclusions? - Ecol. Res. 23: 635-639.

Osko, T. J. et al. 2004. Moose habitat preferences in response to changing availability. - J. Wildl. Manage. 68: 576-584.

Peek, J. M. 1997. Habitat relationships. - In: Schwartz, C. C. and Franzmann, A. W. (eds), Ecology and management of the North American moose. - Smithsonian Inst. Press, pp. 351375.

R Development Core Team 2008. R: a language and environment for statistical computing. - Vienna, Austria.

Rolandsen, C. M. et al. 2008. Accuracy and repeatability of moose (Alces alces) age as estimated from dental cement layers. - Eur. J. Wildl. Res. 54: 5-14.

Rosenzweig, M. L. 1991. Habitat selection and population interactions: the search for mechanism. - Am. Nat. 137: S5-S28.

Sæther, B.-E. et al. 1992. The final report from the project "Moose-forest-society". - NINA Forskningsrapport 28.

Sæther, B.-E. et al. 2003. Effects of altering sex ratio structure on the demography of an isolated moose population. - J. Wildl. Manage. 67: 455-466.

Sæther, B.-E. et al. 2004. Offspring sex ratio in moose Alces alces in relation to paternal age: an experiment. - Wildl. Biol. 10: $51-57$.

Download the Supplementary material as file E5783 from $<$ www.oikos.ekol.lu.se/appendix $>$.
Sæther, B.-E. et al. 2007. Estimating the growth of a newly established moose population using reproductive value. - Ecography 30: 417-421.

Schaefer, J. A. and Messier, F. 1995. Habitat selection as a hierarchy: the spatial scales of winter foraging by muskoxen. - Ecography 18: 333-344.

Schwartz, C. C. et al. 1987. Nutritional energetics of moose. - Swed. Wildl. Res. (Suppl.) 1: 265-280.

Senft, R. L. et al. 1987. Large herbivore foraging and ecological hierarchies. - BioScience 37: 789-799.

Solberg, E. J. et al. 2008. Lack of compensatory body growth in a high performance moose Alces alces population. - Oecologia 158: 485-498.

Stephen, D. W. and Krebs, J. R. 1986. Foraging theory. - Princeton Univ. Press.

Stewart, K. M. et al. 2002. Temporospatial distributions of elk, mule deer, and cattle: resource partitioning and competitive displacement. - J. Mammal. 83: 229-244.

Tremblay, J.-P. et al. 2007. Fidelity to calving areas in moose (Alces alces) in the absence of natural predators. - Can. J. Zool. 85: 902-908.

Venables, W. N. and Ripley, B. D. 2002. Modern applied statistics with $S$. - Springer.

White, K. S. and Berger, J. 2001. Antipredator strategies of Alaskan moose: are maternal trade-offs influenced by offspring activity? - Can. J. Zool. 79: 2055-2062.

Zweifel-Schielly, B. et al. 2009. Habitat selection by an Alpine ungulate: the significance of forage characteristics varies with scale and season. - Ecography 32: 103-113. 